\title{
Successful management of Halyomorpha halys (Hemiptera: Pentatomidae) in commercial apple orchards with an attract-and-kill strategy
}

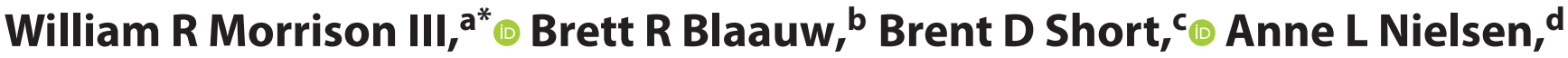 \\ James C Bergh, ${ }^{\mathrm{e}}$ Greg Krawczyk, ${ }^{\mathrm{f}}$ Yong-Lak Park, ${ }^{\mathrm{g}}$ Bryan Butler, ${ }^{\mathrm{h}}$ \\ Ashot Khrimian' and Tracy C Leskeyc
}

\begin{abstract}
BACKGROUND: Introduction of Halyomorpha halys (Stål) in the USA has disrupted many established integrated pest management programs for specialty crops, especially apple. While current management heavily relies on insecticides, one potential alternative tactic is attract-and-kill (AK), whereby large numbers of $\boldsymbol{H}$. halys are attracted to and retained in a circumscribed area using attractive semiochemicals and removed from the foraging population with an insecticide. The goal of this study was to evaluate if AK implementation in commercial apple orchards can result in levels of $H$. halys damage that are equal to or less than those from grower standard management programs.
\end{abstract}

RESULTS: Over 2 years at farms in five Mid-Atlantic USA states, we found that the use of AK resulted in 2-7 times less damage compared with grower standard plots, depending on year and period. At selected trees on which AK was implemented, over $10,000 \mathrm{H}$. halys individuals were killed in two growing seasons, and the use of AK reduced the crop area treated with insecticide against $H$. halys by $\mathbf{9 7 \%}$. Using AK had no impact on the natural enemy or secondary pest community over the same period.

CONCLUSIONS: Overall, the use of AK was effective at managing low to moderate $\boldsymbol{H}$. halys populations in apple orchards, but must be optimized to increase economic feasibility for grower adoption.

(c) 2018 Society of Chemical Industry

Supporting information may be found in the online version of this article.

Keywords: behaviorally-based management; brown marmorated stink bug; integrated pest management; pheromones; semiochemicals

\section{INTRODUCTION}

The unexpected introduction and establishment of a destructive invasive pest species often forces researchers and growers to rapidly develop alternative management tactics, as has been true for the brown marmorated stink bug, Halyomorpha halys (Stål) (Hemiptera: Pentatomidae). Halyomorpha halys were accidentally imported from China ${ }^{1}$ to the USA ${ }^{2}$ in the late 1990s through four separate events, ${ }^{3}$ and it has spread to 44 USA states. It feeds on $>170$ host plants, including many important food crops (www .stopbmsb.org), and in 2010 its infestation of fruit and vegetables reached outbreak status, causing about $\$ 37$ million in damage to USA Eastern apples. ${ }^{4}$ Injury in apple usually consists of hardened, inedible necrotic flesh (termed internal corking, hereafter), with characteristic stylet penetration in the fruit, and discolored dimpling at the site of feeding. ${ }^{5,6}$ Both adult and nymphal $H$. halys inflict damage on tree fruits during the cropping period. ${ }^{6}$ In response, growers applied as much as four times more insecticide to ameliorate this damage. ${ }^{7}$ Since then, $H$. halys has become a problem in Canada ${ }^{8}$ and Europe, ${ }^{9}$ with a projected global distribution to result in range expansion into many more locations. ${ }^{3,10-12}$

Since 2010, pheromone-based technology for $\mathrm{H}$. halys has developed rapidly. ${ }^{13}$ Prior to 2012 , large wooden pyramid traps ${ }^{14}$ baited
* Correspondence to: WR Morrison III, Pest Management Science, USDA-ARS Center for Grain and Animal Health Research, 1515 College Avenue, Manhattan, KS 66502, USA. E-mail: william.morrison@ars.usda.gov

a USDA, Agricultural Research Service, Center for Animal Health and Grain Research, Manhattan, KS, USA

b Department of Entomology, University of Georgia, Athens, GA, USA

c USDA, Agricultural Research Service, Appalachian Fruit Research Station, Kearneysville, WV, USA

d Department of Entomology, Rutgers Agricultural Research and Extension Center, Rutgers University, Bridgeton, NJ, USA

e Virginia Tech, Alson H. Smith, Jr. Agricultural Research and Extension Center, Winchester, VA, USA

f Department of Entomology, Fruit Research and Extension Center, Pennsy/vania State University, Biglerville, PA, USA

g Division of Plant \& Soil Sciences, West Virginia University, Morgantown, WV, USA

h Carroll County Cooperative Extension, University of Maryland, Westminster, $M D, U S A$

i USDA, Agricultural Research Service, Beltsville Agricultural Research Center, Beltsville, MD, USA 
with methyl $(E, E, Z)$-2,4,6-decatrienoate (MDT, hereafter) were used to monitor $H$. halys populations. More recently, the male-produced $H$. halys aggregation pheromone was identified as a mixture of two stereoisomers of 10,11-epoxy-1-bisabolen-3-ol (aggregation pheromone, hereafter). ${ }^{15}$ When the aggregation pheromone and MDT were combined in traps, a synergistic effect on field attraction of $H$. halys adults and nymphs was observed. ${ }^{16}$ This combination reliably captured all life stages and sexes of $H$. halys throughout the growing season in the USA, ${ }^{17}$ Europe $^{18}$, and Asia. ${ }^{19}$

Halyomorpha halys often invades fields from wild hosts in the landscape, and is usually most abundant along crop field edges. $^{20-22}$ For example, $H$. halys densities were much greater at the borders than the interior of peach orchards, with males primarily driving this pattern. ${ }^{22}$ In apple, most injury was along the edges of orchards in the Mid-Atlantic region of the USA. ${ }^{21}$ Rice et al. ${ }^{23}$ documented that forest shape and size in the landscape surrounding commercial tomato fields significantly influenced stink bug damage. As a result, monitoring for $H$. halys is often along the edges of fields and orchards to intercept the pest.

Alternative management tactics that exploit the perimeter-driven behavior exhibited by $H$. halys have been investigated. One such tactic uses weekly border insecticide applications in peach orchards along with a suite of other integrated pest management (IPM) tactics to reduce overall insecticide usage. ${ }^{24}$ Nielsen et al. ${ }^{25}$ demonstrated a differential attraction of $H$. halys to various crops, particularly sorghum and sunflower. However, trap cropping using a border of sunflower and sorghum, ${ }^{26,27}$ which have been shown to arrest $H$. halys movement into the cash crop, $^{28}$ was not successful at reducing damage to bell peppers.

Pheromone-based technology is also being used for $\mathrm{H}$. halys management. For example, captures in pheromone-baited pyramid traps on the exterior and interior of apple orchards have been used to trigger alternate row middle (ARM) sprays over 2 weeks based on a cumulative provisional threshold. ${ }^{29}$ This can reduce insecticide usage by $40 \%$ while maintaining crop quality. Attract-and-kill (AK) involves attracting adults and nymphs to a spatially circumscribed area and removing them via regular pesticide applications. Morrison et al..$^{30}$ evaluated the behavioral basis of AK for $H$. halys in a research orchard and found: (i) a pheromone dose-dependent increase in kill at baited trees, (ii) minimal spillover of adults, nymphs, and damage into adjacent trees, and (iii) a high, season-long average kill of adults at baited trees. Indeed, over 25,000 H. halys adults were killed at six baited trees with $1000 \mathrm{mg}$ of $H$. halys aggregation pheromone over a 6-day period. ${ }^{30}$ AK has been used to manage pests in other systems, including Ceratitis capitata Wiedemann (Diptera: Tephritidae) in citrus orchards in Spain, ${ }^{31}$ Rhagoletis pomonella (Walsh) (Diptera: Tephritidae) ${ }^{32}$ and Conotrachelus nenuphar (Herbst) (Coleoptera: Curculionidae) ${ }^{33}$ in northeastern USA apple orchards, Rhynchophorus ferrugineus (Olivier) (Coleoptera: Curculionidae) on date palm plantations in Saudi Arabia, ${ }^{34}$ and Phthorimaea operculella (Zeller) (Lepidoptera: Gelechiidae) in potato fields in Peru and Australia. ${ }^{35}$ These studies illustrate that AK can be used successfully in a variety of systems, under different abiotic conditions, and against a variety of taxa. The goal of the current study was to demonstrate the effectiveness of AK in reducing $H$. halys damage to levels that were equal to or less than grower standard management programs in commercial apple orchards in five USA Mid-Atlantic States.
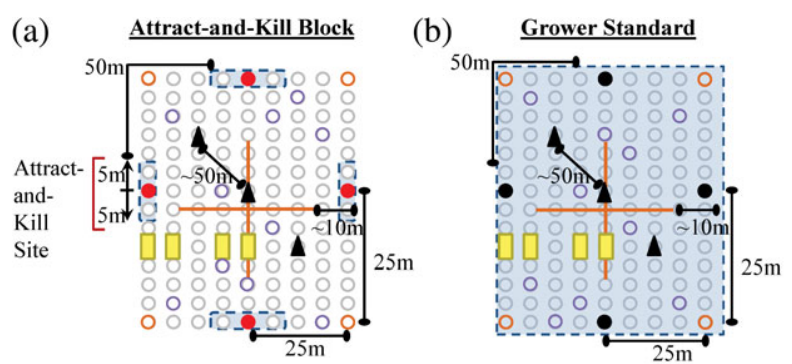

$i i=$ Area treated with insecticide = Baited monitoring pyramid trap $=$ Tarp at baited AK tree

= Tarp at unbaited tree

$-=$ Interior trees with fruit harvests $\bigcirc=$ Perimeter trees with fruit harvest $\square=$ Yellow sticky card deployments

$\mathrm{O}=$ Randomly selected trees

for mite sampling

Figure 1. Sampling schematic for a) attract-and-kill (AK) and b) grower standard blocks on commercial farms in 2015-2016. Schematic is representative of key features, but not to scale.

\section{MATERIALS AND METHODS}

\subsection{Study sites and sampling periods}

This study included 10 commercial apple farms in five Mid-Atlantic States in the USA (Table S1 in the supporting information, Fig. 1). The farms included in this study were all commercial operations ranging from low- to high-density plantings, and included a variety of end uses, such as fresh market, processing, and pick-your-own agritourism operations. The study was conducted from 1 June to 14 October 2015 and 6 June to 30 September 2016. Sampling in these 2 years presented a test of AK under low population pressure in 2015 and 2.5-27× higher population pressure in 2016 (Fig. 2, Fig. 3).

\subsection{Grower standard blocks}

On each farm, one orchard was randomly assigned as the grower standard (control) block and another as the attract-and-kill (AK, treatment) block (Fig. 1). In the standard blocks, H. halys management programs were solely determined by each grower. Management of other orchard insects and diseases followed standard local extension recommendations $\mathrm{s}^{36}$ and were identical between the standard and AK blocks within a farm.

\subsection{Attract-and-kill blocks}

In each AK block, AK sites were spaced every $50 \mathrm{~m}$ around the perimeter of the orchard, except on the fourth internal edge on farms in cases where orchards were bisected to create two plots. At each AK site in an orchard, a tree was baited with $840 \mathrm{mg}$ of aggregation pheromone, which was distributed on the perimeter-facing aspect of the tree as 20 high-dose pheromone lures ( $42 \mathrm{mg}$ per lure) of the stereoisomeric mixture of cis-(7R)-10,11-epoxy-1-bisabolen-3-ols incorporated into $12 \times 6.5 \mathrm{~cm}$ fiber pads (ChemTica, Inc., Heredia, Costa Rica). ${ }^{13,30}$ In addition, each baited tree had one lure containing $66 \mathrm{mg}$ of the pheromone synergist, MDT incorporated into a semi-permeable sachet (AgBio, Inc., Westminster, CO, USA). The lures were covered with 473-mL plastic cups (Dart Container Corps, Mason, MI) for rain protection, and hung in the tree with twist ties. Both types of lures were replaced every 4 weeks during the sampling period. From the beginning of experimentation in June to the last fruit harvest in September or October (depending on the field, grower, and year), grower cooperators applied insecticide weekly to the outward facing portion of the pheromone-baited tree and trees within $5 \mathrm{~m}$ on either side, which together comprised each AK 
site. All seasonal insecticide programs followed legal regulations (Table $\mathrm{S} 2$ in the supporting information).

\subsection{Monitoring traps}

In 2015 and 2016, three black pyramid traps (1.22 m tall; AgBio, Inc., Westminster, CO, USA) were deployed with a grey rubber septum lure impregnated with $31 \mathrm{mg}$ of crude murgantiol (aggregation pheromone mimicking lure \#11 in Leskey et $a l_{.0}^{37}$ ), containing $2 \mathrm{mg}$ and $3.2 \mathrm{mg}$ of (3S,6S,7R,10S)-10,11-epoxy-1-bisabolen-3-ol and $(3 R, 6 S, 7 R, 10 S)$-10,11-epoxy-1-bisabolen-3-ol, respectively. A separate lure containing $66 \mathrm{mg}$ of MDT (AgBio, Inc.) was deployed in the same traps. Along with the lures, a $5-\mathrm{cm}$ kill strip containing 10\% 2,2-dichlorovinyl dimethyl phosphate (Vaportape II, Hercon, Emigsville, PA) was also deployed in the collection jar at the apex of the pyramid trap to retain captured $H$. halys (see Morrison et al. $2015^{38}$ for physical specifications of the trap). The aggregation pheromone and kill strips were changed at 2-week intervals, and the MDT was replaced every 4 weeks. Traps were positioned in a diagonal transect through the center of the block and between apple trees in the rows, spaced approximately $50 \mathrm{~m}$ apart depending on block configuration, and checked weekly for adults and nymphs. The season was divided into three periods: early (initiation-30 June), mid (1 July-15 August), and harvest (16 August-15 October). Traps were used to trigger two ARM sprays to the whole block (one per week) if $H$. halys captures reached or exceeded a cumulative threshold of 10 adults per trap, after which the threshold was reset and insecticide applications to the AK sites resumed. ${ }^{29}$

\subsection{Fruit sampling}

All apple cultivars selected for the study matured and were harvested from late September to early October to ensure that there would be comparable levels of exposure to feeding by $H$. halys in the AK and grower standard blocks. Three fruit samples were collected during both growing seasons (5-6-week intervals), in mid-July, mid-August, and at harvest (September-October) (Table S1 in the supporting information). The harvest sample was taken when a majority of the cultivars were ripe and/or if more than one block edge was to be fully harvested. For each sample, fruit were collected from 16 interior and four perimeter trees, with the perimeter trees at approximately $25 \mathrm{~m}$ away from a pheromone-baited tree in the AK blocks. Initial placement of AK sites was randomized at the beginning of each season, and subsequently sampled thereafter through the season. In blocks that were bisected to form a grower standard or AK block, a fourth edge was lacking, and thus, only three perimeter trees were sampled for fruit. For all blocks, interior samples were harvested from trees in two intersecting perpendicular transects, with eight trees sampled per transect, although this varied slightly by block configuration. The initial selection of trees in a transect was randomized at the beginning of a season, but in every case, trees were spaced to span the interior of the block (approximately $10 \mathrm{~m}$ from the edge to the center of the block; Fig. 1), with actual spacing depending on the block size. These trees were flagged and subsequently sampled in the early, mid, and harvest periods. Because of logistical constraints from commercial production in the orchards, it was impossible to randomize the selection of trees between each sample, but this method ensured that we had a representative sample of fruit from the entire block. Ten random fruit per tree were harvested from the mid- to upper-canopy, where damage is often most severe, ${ }^{21}$ thus making fruit damage reduction estimates conservative. The proportion of injured fruit (frequency of damage) and the

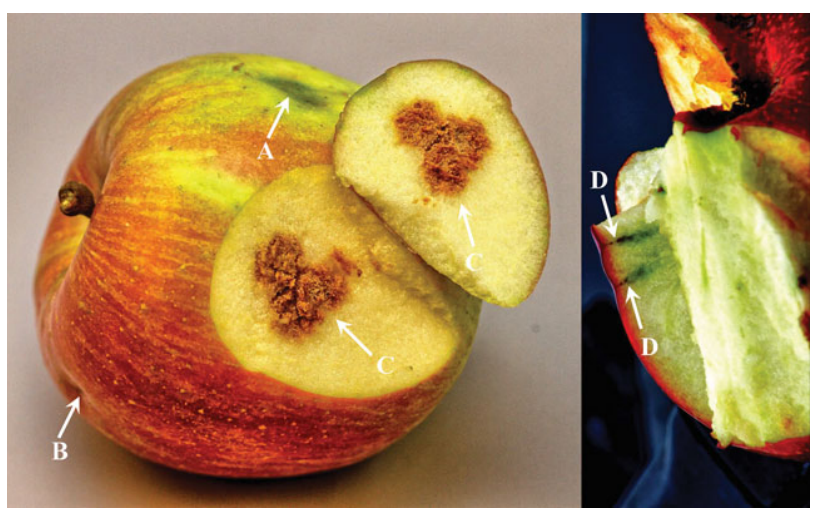

Figure 2. Diagnostic pictures of $H$. halys feeding damage on apple, including (A) discoloration of the flesh, (B) discolored dimpling, (C) internal corking (measured in this study), and (D) characteristic stylet penetration trail into the apple's flesh just below the surface of the skin.

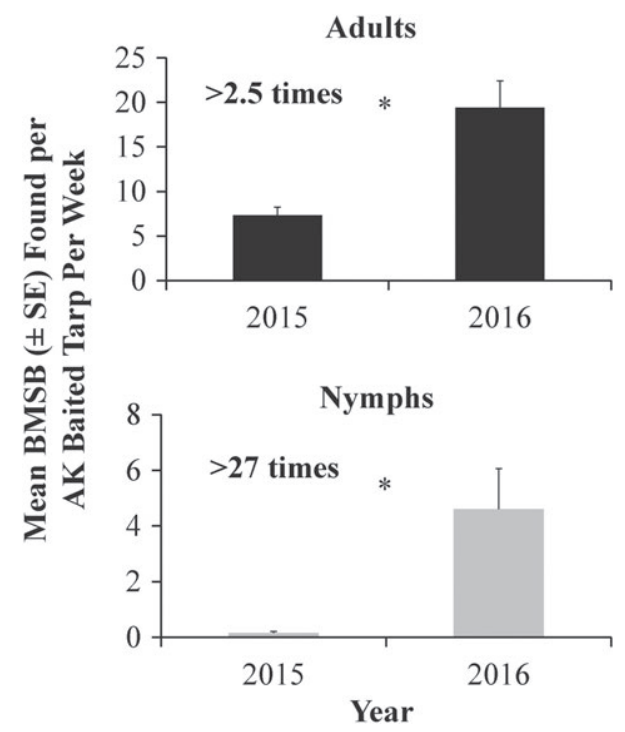

Figure 3. Difference in $H$. halys population pressure between sampling in 2015 and 2016 as measured by overall mean numbers of dead adults on tarps beneath baited attract-and-kill trees on 3-4 commercial apple orchards in the Mid-Atlantic region of the USA. Asterisks indicate significant differences between years ( $t$-test, $\alpha=0.05$ ).

number of internal corking sites per fruit (severity of damage) was recorded (see Fig. 2 for diagnostic injury pictures). Due to poor fruit set in 2016, samples were only collected during harvest from two farms, while three fruit samples were taken from all others.

\subsection{Mortality of $\boldsymbol{H}$. halys at attract-and-kill trees}

To measure mortality of $H$. halys at baited AK trees, tarps were secured beneath 5-7 baited trees and compared with unbaited trees in the standard block on 3-4 farms across the same number of states in the USA. Tarps in both treatments were placed on the perimeter of blocks, with identical spacing, and number within a farm. Tarps ranged in size from $2.1 \times 3.0$ to $3.7 \times 4.3 \mathrm{~m}$ (W:L), spanned the entire lower canopy of trees, and were checked weekly for the number of $H$. halys adults and nymphs.

\subsection{Natural enemy and secondary pest assessment}

In 2015 and 2016, natural enemies were sampled using yellow $23 \times 14 \mathrm{~cm}$, back-folding sticky cards (Alpha Scents, Inc, West Linn, 
OR, USA). Four cards (two in the interior third and two on the exterior of the block) were deployed per block three times during the season: 14-22 June, 6-25 July, and 3-26 August, depending on the year and block. After 1 week, the cards were recovered and held at $-4{ }^{\circ} \mathrm{C}$ until they could be processed, when the number of predators and parasitic wasps on each were recorded. All taxa primarily classified as predators or parasitoids were counted, which may have included each of the following depending on farm: Anthocoridae, Asilidae, Bombyliidae, Cantharidae, Carabidae, Coccinellidae, Geocoridae, Nabidae, Neuroptera (lacewings), parasitic wasps (Parasitica), Pentatomidae (predatory), Reduviidae, Sphecidae, Staphylinidae, Syrphidae, Tachinidae, and Vespidae.

Mite sampling occurred in conjunction with the deployment of sticky cards during the three periods described above. Five leaves randomly collected from 10 trees per block at each farm were brushed onto detergent-coated glass plates using standard mite brushing machines in the laboratory. The following herbivorous and predatory mite species were recorded: Panonychus ulmi (Koch), Tetranychus urticae Koch, Zetzellia mali (Ewing), Neoseiulus fallacis (Garman), and other phytoseiid mites.

\subsection{Economic analysis of attract-and-kill technology}

A subset of three farms (one from MD, WV and VA) were chosen for cost analysis to compare AK and grower standard programs for insect management. The categories chosen for analysis were: insecticide cost per ha (Table S3 in the supporting information), cost of lures for baited trees, cost of labor to deploy and replace lures on baited trees, crop loss adjusted for bushels harvested per ha (whole plot and processing loss), and profits based on yield for each experimental plot. At the time of this study, experimental lures cost $\$ 5$ per high-dose $H$. halys aggregation pheromone lure, and $\$ 4.75$ per $66 \mathrm{mg}$ MDT lure. In this economic analysis, apple downgrade to processing was calculated at an $80 \%$ loss in value. Expenses not included were fuel and labor for insecticide application, fruit loss on pheromone-baited trees, and monitoring trap expenses (as trap expenses were identical between the AKand grower standard blocks). Labor to deploy the lures was calculated at $\$ 12 / \mathrm{h} \times 1 \mathrm{~h} \times 4$ changes. Data were computed separately for each year and farm and then averaged across farms within a year. The cost of a bushel of apples was priced at $\$ 20$ for all farms as a fresh market standard in the Mid-Atlantic, USA. ${ }^{39}$ Whole plot applications of insecticides were standardized at $378.5 \mathrm{~L}$ of water per $0.405 \mathrm{ha}$. For the AK tree insecticide applications, the estimated spray volume was conservatively calculated at $37.9 \mathrm{~L}$ per plot for all farms as tree size and number of baited trees varied.

\subsection{Statistical analysis}

Pyramid trap data were analyzed separately by year with a linear mixed model. The number of adults or nymphs per trap was used as the response in the model, with treatment (AK and grower standard) and sampling period (early, mid, and harvest) as fixed explanatory variables. The interaction between treatment and sampling period was also included in the model. Orchard site was used as a random blocking variable. Date was used as a repeated measure in the analysis, with a first-order autoregressive correlation/covariance matrix. Because data did not conform to the assumptions of a normal distribution upon inspection of residuals, they were log-transformed, after which assumptions were fulfilled. Upon a significant result from the overall model, Tukey's HSD was used for pairwise comparisons. This same procedure was used to analyze the mortality of $H$. halys adults and nymphs that were killed on tarps, except for nymphs in 2015, which were inverse-transformed instead of log-transformed.

The proportion of injured fruit per tree was analyzed separately each year with a generalized linear mixed model. The model structure was the same as above for the severity of damage. However, because initial analysis revealed that overdispersion was a problem with the model, a quasi-binomial distribution was used to model the data which corrects for this issue. ${ }^{40}$ Likelihood ratio tests based on a $\chi^{2}$-distribution were used to test the significance of the variables in the model. Post-hoc pairwise comparisons were performed with $\chi^{2}$-tests using a Bonferroni correction.

The severity of damage from the fruit sampling was analyzed separately for each year using a linear mixed model. The number of internal corking sites per fruit was used as the response variable, with the treatment, sampling period, and location of the tree (perimeter or interior) as fixed explanatory variables. The second-order and third-order interactions were also included in the model. The field site was coded as a random blocking variable. Upon inspection of the residuals, the data were log-transformed to correct deviations from normality. Upon a significant result from the model, Tukey's HSD was used for pairwise comparisons.

Predators and parasitoids recorded from sticky traps were analyzed separately. A linear mixed model was used to analyze each response variable in each year, particularly using treatment and sampling period as fixed, explanatory variables. The two-way interaction between these variables was also included. Field site was used as a random, blocking variable. Upon inspection of the residuals, the data were log-transformed to correct deviations from normality. Upon a significant result from the model, Tukey's HSD was used for pairwise comparisons. The same procedure was used to analyze the mite data, using herbivorous mite species as one response variable, and predatory mite species as another response variable. For this and all other statistical analyses, $\mathrm{R}$ software ${ }^{41}$ was used with $\alpha=0.05$.

\section{RESULTS}

\subsection{Monitoring traps}

In 2015, there was no significant difference between the treatments in the mean number of adults captured $\left(F_{1,49}=3.74\right.$; $P=0.053$; Fig. 4(a)) but captures varied significantly by sampling period $\left(F_{2,274}=27.5 ; P<0.0001\right.$; Fig. $\left.4(a)\right)$. In particular, there were 7 and 10 times more adults captured in the harvest period, compared with the early or mid-period, respectively. There was no significant period by treatment interaction $\left(F_{2,274}=2.59\right.$; $P=0.075$ ). Nymphs were not consistently recorded across all blocks in 2015, and are thus not reported. Across all plots in 2015, threshold was reached a total of 16 times in grower standard plots, while it was only reached seven times in AK plots, which was significantly less $\left(\chi^{2}=3.62 ; \mathrm{df}=1 ; P<0.05\right)$.

In 2016, there was no significant difference between the treatments in the mean number of adults captured $\left(F_{1,49}=1.45\right.$; $P=0.229$; Fig. $4(b))$, but the period during which traps were deployed affected captures significantly $\left(F_{2,274}=223.8 ; P<0.0001\right.$; Fig. 4(b)). Specifically, approximately five and 12 times more adults were captured in the harvest period compared with the early and mid-period, respectively. The interaction between sampling period and treatment was significant $\left(F_{2,274}=3.55\right.$; $P<0.05)$. Similar to adults, treatment did not significantly affect captures of nymphs $\left(F_{1,49}=0.891 ; P=0.345\right)$, although there was a significant effect of sampling period on nymphal captures $\left(F_{2,274}=367.3 ; P<0.0001\right)$. Approximately 180 and four 
(a)

\section{$\underline{2015}$}

(b)

$\underline{2016}$

Early
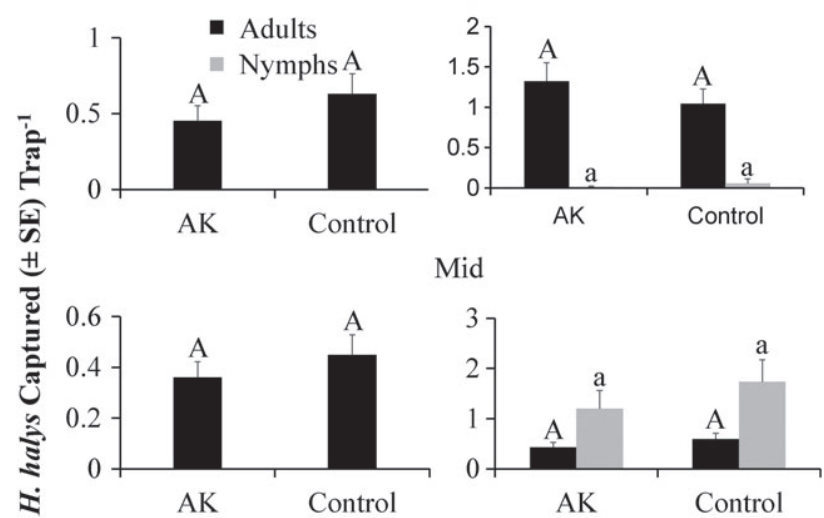

3

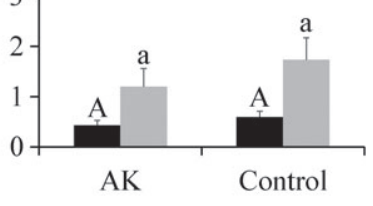

Harvest
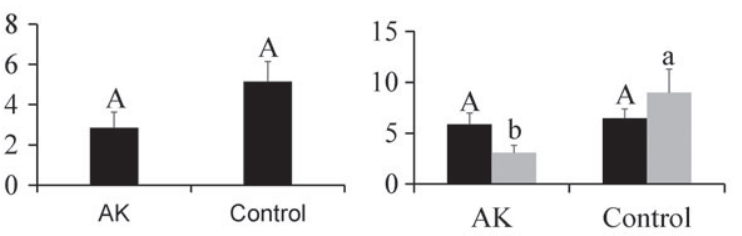

Treatment

Figure 4. Mean adult $H$. halys captured in monitoring pyramid traps located in each block on 10 farms in five Mid-Atlantic states in the USA from 11 May to 14 October 2015 (a) and 31 May to 11 October 2016 (b). Letters represent comparisons within life stages. Bars with shared letters were not significantly different from each other (Tukey's HSD, $\alpha=0.05$ ). Nymphs were not displayed in 2015, because they were only counted at a subset of orchards. $\mathrm{AK}=$ attract-and-kill block, $\mathrm{Control}=$ grower standard block.

times more nymphs were captured during the harvest period than either the early or mid-periods, respectively. There was a significant interaction between treatment and sampling period $\left(F_{2,274}=124.4 ; P<0.0001\right)$, with over two times more nymphs captured in grower standard blocks than in AK blocks in the midand harvest period, but not in the early period. Across all plots in 2016, there was not a significant difference in the number of times threshold was reached in AK plots (18 times) compared to grower standard plots ( 19 times; $\chi^{2}=0.027 ; \mathrm{df}=1 ; P=0.87$ ).

\subsection{Proportion of injured fruit}

Treatment significantly affected the proportion of injured fruit $\left(\chi^{2}=4.43 ; \mathrm{df}=1 ; P<0.04\right.$; Fig. 5(a)), almost halving the proportion of fruit damaged per tree in the AK blocks compared with the grower standard. Tree location influenced the proportion of damage $\left(\chi^{2}=13.5 ; \mathrm{df}=1 ; P<0.001\right)$, with 1.6 times more damage on trees on the perimeter of blocks. Sampling period also significantly affected the proportion of fruit damage $\left(\chi^{2}=84.6\right.$; $\mathrm{df}=2 ; P<0.0001)$; damage was three times more frequent on trees sampled in the mid- and harvest period compared with the early period. The two-way interactions involving treatment were not significant by location $\left(\chi^{2}=0.01 ; \mathrm{df}=1 ; P=0.914\right)$ or period $\left(\chi^{2}=1.55 ; \mathrm{df}=2 ; P=0.462\right)$. The two-way interaction between location and period was significant $\left(\chi^{2}=11.0 ; \mathrm{df}=2 ; P<0.01\right)$, as was the three-way interaction among all the variables $\left(\chi^{2}=7.70\right.$; $\mathrm{df}=4 ; P<0.03)$.

Likewise, in 2016, the proportion of fruit damage on trees depended on the treatment $\left(\chi^{2}=9.12 ; \mathrm{df}=1 ; P<0.01 ;\right.$ Fig. 5(b)); on average, there was almost half as much damage on trees in the (a) $\underline{\mathbf{2 0 1 5}}$

(b)

$\underline{2016}$
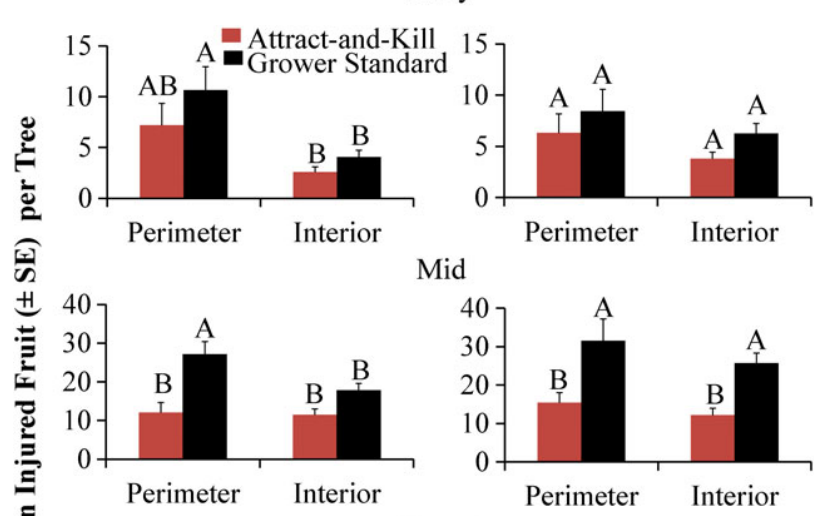

Harvest

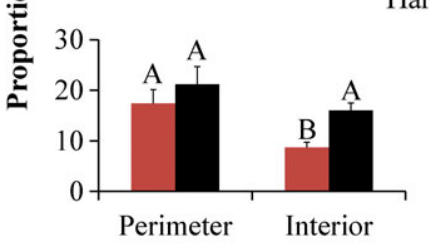

Tree Location

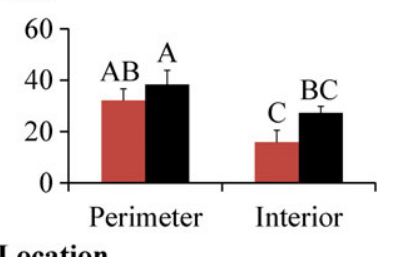

Figure 5. Proportion of injured fruit per tree in the early (13 July to 15 July; top panels), mid- (25 August to 2 September; middle panels), and harvest period (17 September to 1 October; bottom panels) at 10 commercial apple orchards in five Mid-Atlantic States of the USA in 2015 (a) and 2016 (b) for attract-and-kill managed blocks (red) and grower standard blocks (black). Bars with shared letters were not significantly different from each other ( $\chi^{2}$-test with Bonferroni correction).

AK blocks compared with the grower standard block. Tree location also significantly influenced the proportion of damage $\left(\chi^{2}=4.22\right.$; $\mathrm{df}=1 ; P<0.05)$, with 1.5 times more frequent damage on perimeter than interior trees. The period during which the tree was sampled also affected the proportion of fruit damage $\left(\chi^{2}=119.5\right.$; $\mathrm{df}=2 ; P<0.0001$; Fig. 5(b)), with three and four times more damage in the mid- and harvest period, respectively, compared with the early period. None of the two-way interactions were significant (treatment $\times$ location: $\chi^{2}=0.426 ; \mathrm{df}=1 ; P=0.514$; treatment $\times$ period: $\chi^{2}=5.93 ; \mathrm{df}=2 ; P=0.052$; location $\times$ period: $\chi^{2}=0.5 .83$; $\mathrm{df}=2 ; P=0.054)$. The three-way interaction among each of the variables was also not significant $\left(\chi^{2}=1.26 ; \mathrm{df}=2 ; P=0.533\right)$.

\subsection{Fruit damage severity}

A similar pattern was detected with the severity of damage found on trees. In 2015, a total of 9990 fruit were harvested over the course of the experiment. Importantly, the treatment significantly affected the severity of damage on fruit $\left(F_{1,398}=408.1\right.$; $P<0.0001$; Fig. 6(a)); overall, less than half the number of internal corking sites were recorded on fruit collected from the AK block compared with the grower standard block. Tree location also significantly influenced damage severity $\left(F_{1,398}=663.8\right.$; $P<0.0001)$, with almost twice as much damage on perimeter trees compared with interior trees. Additionally, sampling period also significantly influenced fruit damage severity $\left(F_{2,398}=4421\right.$; $P<0.0001)$; there were over four times more internal corking sites during the harvest compared with the early period. There was a significant two-way interaction between treatment and tree location $\left(F_{1,398}=739.1 ; P<0.0001\right)$, treatment and sampling period $\left(F_{2,398}=1572 ; P<0.0001\right)$, and location and sampling 
(a)

$\underline{2015}$

(b)

$\underline{2016}$

Early
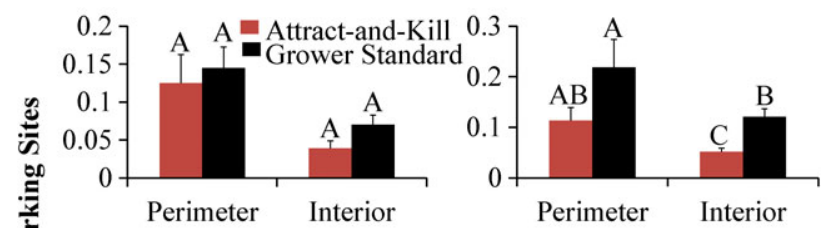

Mid
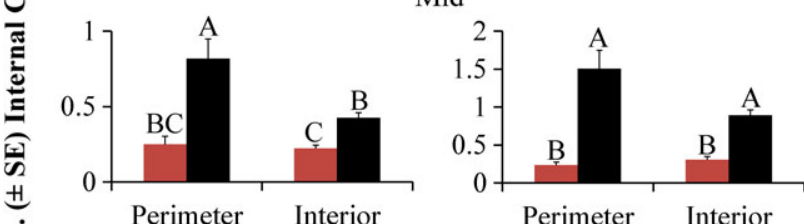

Harvest
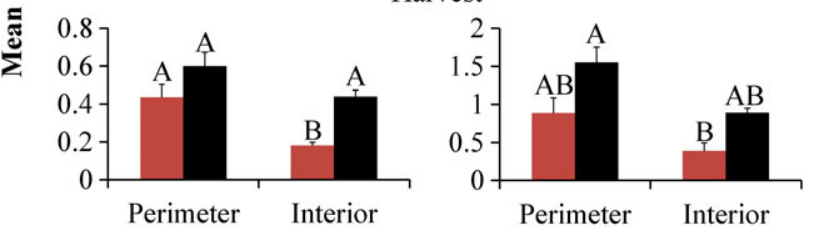

Tree Location

Figure 6. Severity of internal damage per fruit in the early (13 July to 15 July; top panels), mid- (25 August to 2 September; middle panels), and harvest period (17 September to 1 October; bottom panels) at 10 commercial apple orchards in five Mid-Atlantic States of the USA in 2015 (a) and 2016 (b) for attract-and-kill managed blocks (red) and for grower managed blocks (black). Bars with shared letters were not significantly different from each other (Tukey's HSD, $\alpha=0.05$ ).

period $\left(F_{2,398}=121.1 ; P<0.0001\right)$. Finally, there was also a significant three-way interaction among the variables $\left(F_{4,398}=1618\right.$; $P<0.0001)$.

In 2016, a total of 9240 fruit were collected during the experiment. As in 2015, the treatment significantly affected fruit damage severity $\left(F_{1,400}=770.0 ; P<0.0001\right.$; Fig. $\left.6(\mathrm{~b})\right)$, reducing the number of internal corking sites by 2.5 times on fruit collected from the AK blocks compared with the grower standard control. Moreover, tree location affected the damage severity $\left(F_{1,400}=14.8\right.$; $P<0.001)$, with 1.7 times more damage on fruit collected from the perimeter than the interior of the orchard. Furthermore, the sampling period significantly influenced the amount of damage present $\left(F_{2,400}=3192 ; P<0.0001\right)$. Specifically, there was over seven times more damage on fruit in the harvest period compared with the early period. All two-way interactions were significant, for example treatment $\times$ location $\left(F_{1,400}=628.5 ; P<0.0001\right)$, treatment $\times$ period $\left(F_{2,400}=196.2 ; P<0.0001\right)$, and location $\times$ period $\left(F_{2,400}=185.5 ; P<0.0001\right)$, as well as the three-way interaction among all variables $\left(F_{4,400}=1072 ; P<0.0001\right)$.

\subsection{Mortality of $\boldsymbol{H}$. halys at baited attract-and-kill trees}

In 2015 and 2016, 99.6\% and 99.9\% of the dead H. halys adults, respectively, were from tarps beneath baited AK trees. Not surprisingly, treatment had a significant influence on the mortality of adults in both $2015\left(F_{1,45}=33.9 ; P<0.0001\right.$; Fig. $\left.7(\mathrm{a})\right)$ and $2016\left(F_{1,40}=16.2 ; P<0.0001\right.$; Fig. 7(b)), with 113 and 1630 times more adults killed on AK trees than grower standard trees, respectively. In addition, the number of adults recovered on tarps differed by sampling period in $2015\left(F_{2,523}=32.2 ; P<0.0001\right)$ and $2016\left(F_{2,576}=147.0 ; P<0.0001 ;\right.$ Fig. 7). Over five and 15 times more adults were killed in the 2015 harvest period compared with (a)

$\underline{2015}$

(b)

Early

$\underline{2016}$

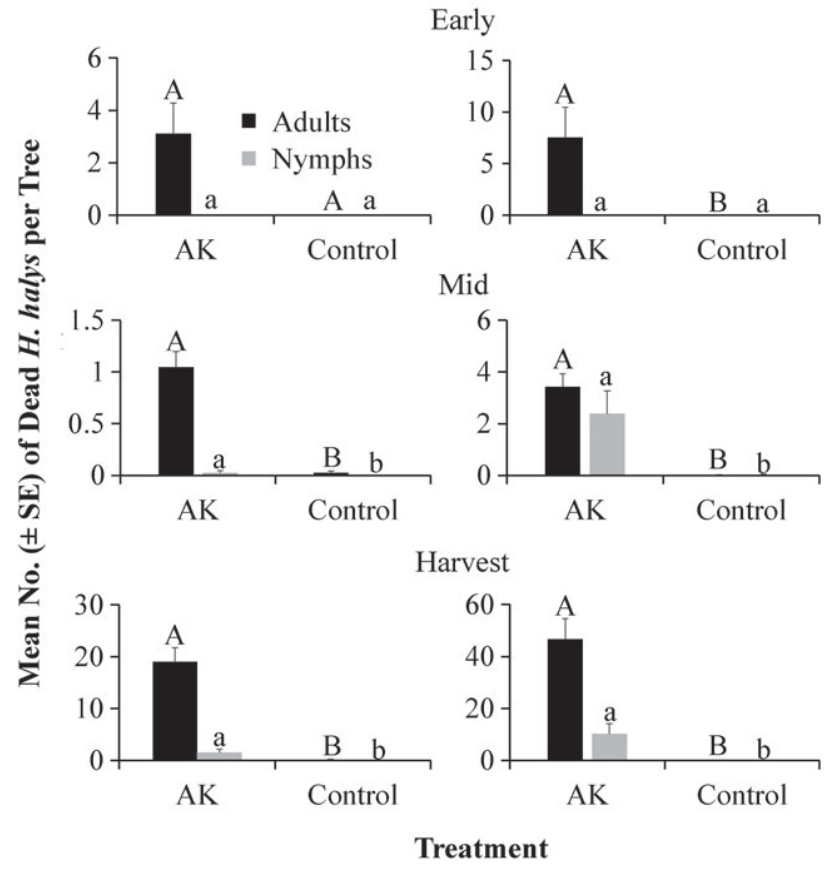

Figure 7. Mean number of dead $H$. halys adult (black) and nymphs (grey) collected on tarps in the early (top panel), mid- (middle panel), and harvest period (bottom panel) at 3 commercial apple orchards in three Mid-Atlantic States of the USA deployed from 3 June to 21 September 2015 (a) and 6 June to 21 September 2016 (b) for attract-and-kill managed blocks and for grower managed blocks. Letters represent pairwise comparisons within each life stage, and bars with shared letters are not significantly different from each other (Tukey's HSD, $\alpha=0.05$ ). AK, attract-and-kill; Control, grower standard block.

the early and mid-period, respectively, while seven and 14 times more adults were killed in the 2016 harvest period compared with the same two periods. There was a significant treatment $\times$ sampling period interaction in $2015\left(F_{1,523}=15.2 ; P<0.0001\right)$ and 2016 $\left(F_{1,576}=30.0 ; P<0.0001\right)$. There were 216 and 1988 times more adults killed on AK trees in the 2015 and 2016 harvest period, respectively, compared to grower standard trees.

In 2015 and $2016,98.3 \%$ and $99.7 \%$ of the dead $H$. halys nymphs were found on baited AK trees, respectively. Treatment significantly influenced the mortality of nymphs in $2015\left(F_{1,45}=1497\right.$; $P<0.0001$; Fig. 7(a)) and $2016\left(F_{1,40}=158.8 ; P<0.0001\right.$; Fig. $\left.7(b)\right)$, with 60 and 290 times more nymphs killed on AK trees than grower standard trees in 2015 and 2016, respectively. The sampling period also significantly affected mortality of nymphs on trees in 2015 $\left(F_{2,523}=1524 ; P<0.0001\right)$ and $2016\left(F_{1,576}=153.1 ; P<0.0001\right)$, with 15 and 10 times more nymphs killed in the harvest period compared to the mid-period, respectively. There was a significant interaction between treatment and sampling period in 2015 $\left(F_{1,523}=9474 ; P<0.0001\right)$ and $2016\left(F_{1,576}=52.5 ; P<0.0001\right)$. In particular, while mortality during the early season was statistically equivalent between the treatments, not a single nymph was killed in the control treatment under grower standard trees in the midand harvest period.

\subsection{Natural enemy assessment}

An average of $9.7 \pm 1.6$ (mean $\pm \mathrm{SE}$ ) and $11.3 \pm 1.3$ predators and parasitic wasps, respectively, were captured on yellow sticky cards in AK blocks, while there were $9.5 \pm 1.1$ and $11.2 \pm 1.7$ in grower 
Table 1. Summary of costs for external inputs in US Dollars for 2015-2016 studies of commercial implementation of attract-and-kill compared to grower standard practices

\begin{tabular}{|c|c|c|c|c|c|c|c|}
\hline \multirow[b]{2}{*}{ Farm } & \multicolumn{2}{|c|}{ Grower standard } & \multicolumn{5}{|c|}{ Attract-and-kill } \\
\hline & WB spray ${ }^{a}$ & Total & WB spray ${ }^{a}$ & Border spray & AgBio lures $^{a}$ & Lure labor & Total \\
\hline \multicolumn{8}{|l|}{2015} \\
\hline MD & 865 & 865 & 390 & 44 & 4646 & 119 & 5199 \\
\hline VA & 489 & 489 & 667 & 59 & 6019 & 119 & 6865 \\
\hline WV & 1077 & 1077 & 625 & 49 & 5674 & 119 & 6467 \\
\hline Mean & 811 & 811 & 561 & 52 & 5446 & 119 & 6178 \\
\hline \multicolumn{8}{|l|}{2016} \\
\hline MD & 195 & 195 & 114 & 25 & 4646 & 119 & 4903 \\
\hline VA & 324 & 324 & 376 & 32 & 6019 & 119 & 6546 \\
\hline WV & 902 & 902 & 833 & 35 & 2716 & 119 & 3702 \\
\hline Mean & 474 & 474 & 440 & 30 & 4460 & 119 & 5048 \\
\hline
\end{tabular}

standard blocks, respectively. Treatment did not significantly affect the abundance of predators (ANOVA: $F_{1,230}=0.239 ; P=0.626$ ) or parasitic Hymenoptera $\left(F_{1,230}=0.756 ; P=0.387\right)$ on sticky cards. However, deployment period did significantly affect the abundance of predators $\left(F_{2,230}=22.3 ; P<0.0001\right)$ and parasitic wasps $\left(F_{2,230}=16.5 ; P<0.0001\right)$. In particular, there were twice as many predators and parasitic wasps in the early season compared with the late season, in both treatments. There was a significant interaction between treatment and period for predators $\left(F_{2,230}=4.10\right.$; $P<0.05)$, but not parasitic wasps $\left(F_{2,230}=1.08 ; P<0.345\right)$.

In 2016, an average of $8.1 \pm 1.2$ (mean $\pm S E$ ) and $13.3 \pm 1.3$ predators and parasitic wasps, respectively, were recorded from yellow sticky cards in the AK blocks compared with $8.3 \pm 1.8$ and $14.9 \pm 2.0$ in the grower standard blocks. Similar to 2015 , the treatment did not significantly influence the abundance of predators (ANOVA: $\left.F_{1,186}=2.08 ; P=0.157\right)$ or parasitic wasps $\left(F_{1,186}=2.79\right.$; $P=0.098)$ captured. In contrast to the prior year, the deployment period affected captures of predators $\left(F_{2,186}=10.6 ; P<0.0001\right)$, but not parasitic wasps $\left(F_{2,186}=1.75 ; P=0.179\right)$. There was no significant interaction between treatment and deployment period for either predators $\left(F_{2,186}=2.40 ; P=0.096\right)$ or parasitic wasps $\left(F_{2,186}=2.19 ; P=0.117\right)$.

\subsection{Secondary pest assessment}

Treatment had no effect on the numbers of herbivorous mites (ANOVA: $F_{1,154}=0.007 ; P=0.933$ ), nor did the sampling period $\left(F_{2,154}=1.62 ; P=0.202\right)$. There was no treatment $\times$ sampling period interaction $\left(F_{2,154}=0.118 ; P=0.889\right)$. Likewise, the treatment did not significantly influence the number of predatory mites (ANOVA: $F_{1,154}=0.683 ; P=0.410$ ), nor did the sampling period $\left(F_{2,154}=2.76 ; P=0.066\right)$. The interaction between the two variables was not significant $\left(F_{2,154}=0.005 ; P=0.995\right)$.

Similar to 2015, neither the presence of AK (ANOVA: $\left.F_{1,156}=0.489 ; P=0.486\right)$ nor the sampling period $\left(F_{2,156}=1.25\right.$; $P=0.290)$ affected the number of herbivorous mites present in 2016. The interaction between treatment and sampling period was not significant $\left(F_{2,156}=1.56 ; P=0.215\right)$. Treatment had no significant influence on the abundance of predatory mites (ANOVA: $\left.F_{1,156}=0.319 ; P=0.574\right)$. However, sampling period significantly affected the abundance of predatory mites $\left(F_{2,156}=16.0\right.$; $P<0.0001)$ in 2016, with 33 times more mites at harvest compared with the early period. The interaction between treatment and sampling period was not significant $\left(F_{2,156}=0.126 ; P=0.882\right)$.

\subsection{Economic analysis of attract-and-kill technology}

In 2015, AK was over seven times more expensive than grower standard practices across the three Mid-Atlantic farms, with lures making up $88 \%$ of the cost of the AK treatment (Table 1). Using the AK strategy decreased monetary crop losses by almost $30 \%$ in 2015 compared with grower standard practices, translating to $\$ 1545-\$ 1933$ in additional value of the crop based on processing and whole crop loss, respectively (Table 2 ). Moreover, the use of AK resulted in $\$ 2685$ greater value in yield over the grower standard treatment (Table 2). However, when the additional cost of experimental AK was included, on average growers would have paid an additional $\$ 2555$ to use AK over standard practices in 2015, which represented $133 \%$ the cost of the grower standard program (Table 3).

In 2016, total cost for the lures in the AK treatment decreased by approximately $\$ 450$ because of fewer baited trees, but the treatment blocks were still over 10 times more expensive than the cost of grower standard tactics (Table 1). The use of AK decreased monetary crop losses by $16 \%$ in 2016 , resulting in $\$ 779-\$ 971$ in additional revenue for growers based on processing loss or whole plot loss, respectively (Table 2). Because 2016 was a higher population year for $H$. halys, growers only gained an average of \$495 in increased yield in the AK compared with the grower standard plots (Table 3). Again, when the cost of each pest management strategy was included, growers paid $\$ 2446$ more to use AK, an increase of $140 \%$ over the price of grower standard practices (Table 3 ).

\section{DISCUSSION}

We have demonstrated that AK can be used to manage $H$. halys in commercial apple orchards with equivalent or, in many cases, superior control to standard grower practices. At harvest in both years, the proportion of injured fruit was equivalent or reduced by half on interior trees in AK compared with grower standard blocks. By the mid- and harvest period, use of AK in both years reduced the severity of fruit damage on interior trees by half to a third compared with the grower standard blocks. Importantly, even in a year with higher pest pressure (e.g. 2016, Fig. 3), with almost three 


\begin{tabular}{|c|c|c|c|c|c|c|}
\hline \multirow[b]{2}{*}{ Farm } & \multicolumn{3}{|c|}{ Grower standard } & \multicolumn{3}{|c|}{ Attract-and-kill } \\
\hline & $\begin{array}{l}\text { Whole bushels } \\
\operatorname{loss}^{\mathrm{a}, \mathrm{b}}\end{array}$ & $\begin{array}{l}\text { Processing } \\
\text { bushels loss }{ }^{\mathrm{b}, \mathrm{c}}\end{array}$ & Plot profits ${ }^{d}$ & $\begin{array}{c}\text { Whole bushels } \\
\text { loss }^{\mathrm{b}}\end{array}$ & $\begin{array}{l}\text { Processing } \\
\text { bushels loss }{ }^{b, c}\end{array}$ & Plot profits ${ }^{d}$ \\
\hline \multicolumn{7}{|l|}{2015} \\
\hline MD & NA & NA & 33393 & NA & NA & 41185 \\
\hline VA & 5847 & 4678 & 11794 & 6027 & 4821 & 19137 \\
\hline WV & 8310 & 6647 & 112310 & 4268 & 3415 & 103281 \\
\hline Mean & 7080 & 5664 & 52499 & 5147 & 4119 & 54534 \\
\hline \multicolumn{7}{|l|}{2016} \\
\hline MD & NA & NA & 33393 & NA & NA & 41185 \\
\hline VA & 7206 & 5765 & 5414 & 5597 & 4478 & 26078 \\
\hline WV & 4838 & 3870 & 111197 & 4505 & 3603 & 30888 \\
\hline Mean & 6022 & 4819 & 50001 & 5051 & 4040 & 32717 \\
\hline \multicolumn{7}{|c|}{$\begin{array}{l}\text { a All losses are season totals on a per ha basis. } \\
\text { b Note: Because grower standard blocks and attract-and-kill blocks were of different sizes within a farm except for MD, the bushels for the larger field } \\
\text { was adjusted down to the equivalent bushels of the smaller field for fair comparisons between treatments. } \\
\text { c Processing losses are discounted at an assumed } 80 \% \text { rate compared to whole block losses. } \\
\text { d Whole plot profits based on bushels produced per ha assuming a price of US } \$ 20 \text { per bushel for fresh market and are expressed on a per ha basis. }\end{array}$} \\
\hline
\end{tabular}

Table 3. Summary of total monetary losses (US Dollars) experienced by growers in MD, VA, and WV from 2015 to 2016, including additional expenses as a result of treatments

\begin{tabular}{|c|c|c|c|c|}
\hline \multirow[b]{2}{*}{ Farm } & \multicolumn{2}{|c|}{ Grower standard } & \multicolumn{2}{|c|}{ Attract-and-kill } \\
\hline & $\begin{array}{l}\text { Whole } \\
\text { loss }^{\text {a }}\end{array}$ & $\begin{array}{c}\text { Processing } \\
\text { loss }\end{array}$ & $\begin{array}{l}\text { Whole } \\
\text { loss }\end{array}$ & $\begin{array}{c}\text { Processing } \\
\text { loss }\end{array}$ \\
\hline \multicolumn{5}{|l|}{2015} \\
\hline MD & 7537 & 6202 & 7299 & 6879 \\
\hline VA & 6336 & 5167 & 12891 & 11686 \\
\hline WV & 9388 & 7725 & 10734 & 9882 \\
\hline Mean & 7754 & 6365 & 10309 & 9481 \\
\hline \multicolumn{5}{|l|}{2016} \\
\hline MD & 5137 & 4149 & 5397 & 5298 \\
\hline VA & 7529 & 6089 & 12143 & 11023 \\
\hline WV & 5740 & 4772 & 8206 & 7304 \\
\hline Mean & 6136 & 5004 & 8582 & 7875 \\
\hline
\end{tabular}

times more $H$. halys than in 2015, AK adequately managed $H$. halys populations. Prior research has demonstrated that a trap-based threshold for $\mathrm{H}$. halys can be used to manage the pest in apple. ${ }^{29}$ We have expanded the utility of the pheromone by demonstrating that its direct use on an attractive host, in combination with a killing agent, was effective at managing $H$. halys under low to moderate population pressure in commercial apple orchards. As a consequence, AK appears to be a promising technique, but requires some refinement.

It is important to consider economic feasibility, which is a significant drawback to this approach. In the economic analysis, we only consider direct, in-season, and up-front costs, but do not include equipment depreciation, land value changes, and other assorted long-term costs. The cost for lures ranged between $\$ 2716-\$ 6019$ per ha and season, which exceeded the costs for the total standard spray program $\left(\$ 195-\$ 1077 \mathrm{ha}^{-1}\right)$. On the other hand, there was less damage in AK plots, which translated to $16-30 \%$ greater revenue for growers than standard management techniques. However, this was not enough to offset the additional costs of lures in AK. If one looks only at lowering the lure cost to negate the monetary difference between the grower standard and AK blocks, the price of the lures would need to drop from $\$ 5446$ to $\$ 2552$ (based on whole block losses) or $\$ 3120$ (processing block losses) per ha to equal standard apple production costs. Given the same number of lures, lure changes, and number of AK sites per ha, and loading of pheromone per lure, the lures would need to cost approximately USD $\$ 3.79-\$ 4.64$ to be competitive against a traditional grower program. It should be noted that another option for growers to increase fruit quality would be to apply additional, well-timed insecticide sprays (each about \$20/acre), which may be a more economical route. According to Short et al. ${ }^{29}$ six well-timed insecticide sprays, costing about $\$ 120$ in total, controlled $H$. halys damage in Mid-Atlantic orchards, and this represents a price target for AK lures to become competitive with grower standard programs. The costs represented in this paper were for experimental, special order lures that were not commercially available. Since then, new synthetic pathways for producing these pheromones have become available and more companies are producing them. It is expected that lure price will continue to drop as synthetic pathways are optimized and more companies begin selling their own products. Other measures may further optimize AK and improve its economic viability. Ultimately, the plume reach of the $H$. halys pheromone will determine how many AK sites would be needed per block, ${ }^{42}$ which may allow for changes to the spacing of AK sites and thereby decrease the amount of pheromone used in the block. AK was deployed early in the season (in early June), but because $H$. halys populations are usually very low at that time, ${ }^{39}$ it may be possible to delay deploying AK until later in the season, potentially cutting lure costs by two thirds. In addition, whereas we used $840 \mathrm{mg}$ of $H$. halys pheromone per baited tree, it may be that AK efficacy can be maintained by using less pheromone per tree, thereby further reducing costs. Moreover, formulation changes may result in season-long lure attractiveness (Leskey and Short, unpublished), thus eliminating the need to replace lures and 
reducing the number of lures required annually. While the distance of attraction to these semiochemicals is currently unknown, ${ }^{35} \mathrm{AK}$ may also act in areawide suppression of $H$. halys, locally depleting individuals on a farm, which may increase the economic viability of this approach. For example, a $40 \mathrm{~km}^{2}$ comprehensive areawide pest management program with at least one AK trap per km yielded $91 \%$ and $61 \%$ reductions in fruit infestation in Hawaii by Ceratitis capitata and Bactrocera dorsalis (Hendel), respectively. ${ }^{43}$ Finally, it may be possible to use AK when it is most needed, perhaps in combination with trap-based thresholds. Hypothetically, this approach would use a sprayable pheromone formulation that could be tank-mixed with an insecticide and that gradually dissipates as the insecticide loses efficacy, thereby creating temporary AK sites (Leskey and Short, unpublished).

Trap cropping shares some similarities with AK, including requiring that pest insects be retained in a spatially circumscribed area and/or be removed from the foraging population to protect a cash crop. Tillman and Cottrell ${ }^{44}$ used pheromone-baited traps in combination with a sorghum trap crop to prevent the dispersal of Euschistus servus (Say) (Hemiptera: Pentatomidae) into cotton, and found that this successfully prevented emigration from sorghum. Researchers have found that a sorghum and sunflower trap crop for $H$. halys (without supplemental pheromone) was not effective at reducing injury under high population pressure. ${ }^{27}$ Blaauw et al. ${ }^{28}$ found that while $H$. halys was initially retained by the same trap crop, adults ultimately dispersed to the cash crop in the absence of other management tactics, but retention may be improved with supplemental pheromone. ${ }^{30}$ Morrison et $a .^{45}$ also found that aggregation pheromone was a more important determinant for retention than host stimuli, thus suggesting that inclusion of pheromone, in addition to an attractive host, is pivotal for retention and adequate management of $H$. halys. Here, we have shown through the observation of $H$. halys on tarps that we can manipulate the pest population in the AK block compared with the grower standard, and concentrate individuals to a few select baited apple trees in the orchard. We have demonstrated that we can attract $H$. halys to a host and retain them long enough to be killed.

In this study, we found significantly greater severity and proportion of injured fruit collected from trees on the perimeter of blocks, regardless of treatment, further supporting the hypothesis of $H$. halys as a perimeter-driven pest. ${ }^{20-22}$ As a result, special consideration for orchard borders seems justified when considering management for this species. We achieved damage suppression on perimeter and interior trees using a perimeter-based AK tactic compared with conventional grower methods. At a select number of AK-baited trees over 2 years, over 10,000 H. halys were killed. This translates to an average of 582 adults and 138 nymphs killed per AK tree over a 5-month period. Presumably, AK sites intercepted $H$. halys adults and nymphs at the border of apple blocks and retained them long enough for exposure to a lethal dose of insecticide, allaying concerns of sublethal exposure to killing agents. ${ }^{46,47}$ Other perimeter-based methods, such as border sprays, have also been successful for managing $H$. halys in peaches ${ }^{24}$ and soybean. ${ }^{48}$

Unexpectedly, use of AK over two seasons neither increased natural enemy nor decreased secondary pest abundance. There are multiple putative explanations for this pattern. For example, AK may need to be implemented over a longer period before improvements to the natural enemy community can be observed. Because natural enemies are highly mobile, it may be possible that more AK blocks in an area would be needed to reap the benefits of decreased insecticide usage and increased refuges.
Indeed, prior work has shown that natural enemies, such as lady beetles, responded to landscape features out to $1.5 \mathrm{~km}$ around a focal field.$^{49}$ In addition, even though sprays targeting $H$. halys were reduced via $\mathrm{AK}$, insecticides for other pests in these orchards may have affected the natural enemy community. It is possible that spraying the borders of the orchard resulted in an effective barrier to the immigration of natural enemies into the AK blocks. However, because only $20 \%$ of the border was sprayed in AK blocks, compared with $100 \%$ of the border in the grower standard blocks whenever sprays were applied, and because prior work using weekly border sprays on the perimeter of peach orchards found no harm to the natural community, ${ }^{24}$ this seems unlikely. Nonetheless, the long-term effect of AK and other insecticide reduction measures, including sprays triggered by trap-based thresholds (either on the border or full block), on the natural enemy community is worthy of further consideration.

For growers with large acreage, AK, as evaluated in this study, may not be feasible because of the prescribed weekly spray schedule and their need to manage diseases regularly. However, the need to spray pheromone-baited trees may be ameliorated by combining pheromone lures with long-lasting insecticide netting as the killing mechanism ${ }^{50}$, by relocating such AK sites to locations outside the orchard, or by using trunk injections of systemic insecticides to kill adult BMSB at baited AK trees without needing to spray, similar to what is done with emerald ash borer, Agrilus planipennis Fairmaire (Coleoptera: Buprestidae). ${ }^{51}$ Such an approach would decrease the need for frequent sprays and replace it with a killing mechanism that has demonstrated effectiveness for potentially the whole growing season. Sprays could also be decreased by linking AK to thresholds based on the pyramid monitoring traps, which have been shown to be effective on their own and which have sparked widespread grower interest and acceptance.

The commercial farms in our study ran through the spectrum of available horticultural and cultural practices in the Mid-Atlantic region, ensuring that our study is representative of apple production in the eastern US. In our study, we had apples under high and low density plantings, and apples destined for processing, fresh market, and U-Pick/agritourism endpoints. Some of the orchards in this study used trellises, while others did not. Sometimes blocks contained multiple cultivars, and more rarely they were a single cultivar. In every case, we selected blocks that had similar harvest dates ranging from late September to early October so that damage measurements were comparable. Moreover, prior work has demonstrated that there may be similar damage among apple cultivars $^{52}$, and $H$. halys abundance on apple cultivars is more similar to each other than abundance of conspecifics on other plant species. ${ }^{53}$ Similarly, other work has found that the $H$. halys aggregation pheromone is more important than tree fruit volatiles in recruiting and retaining conspecifics. ${ }^{45}$ Despite this great diversity in cultural practices, markets, and apple cultivars among farms, it is clear that AK managed $H$. halys populations as well if not orders of magnitude better than grower standard practices within each farm in 2015 and 2016 (e.g. Figs S1 and S2 in the supporting information). In fact, in 36 possible comparisons between AK blocks and grower standard blocks for frequency of damage at each of the farms, the AK blocks performed equally or better than the grower standard in $92 \%$ of the cases over both years. This suggests that the success of AK is robust across commercial horticultural practices.

Overall, we have documented the novel use of pheromone technology in commercial apple orchards in the Mid-Atlantic region of the USA, one of the regions impacted most severely by the invasive H. halys. We have demonstrated that we are able to reduce both 
the proportion and severity of injured fruit under differing population intensity, while reducing the amount of area sprayed for $\mathrm{H}$. halys by $97 \%$. However, the exact deployment methods, amount of pheromone, distance among AK sites, and other considerations need to be optimized to improve the economic viability of AK compared with conventional management. Nonetheless, because other studies have documented that pheromone-based tools are effective at monitoring $H$. halys in other regions of the world beyond the USA, for example in Asia ${ }^{19}$ and Europe ${ }^{18}$, it is likely that AK tactics developed here could be adapted and adopted in other circumstances to manage this invasive species.

\section{ACKNOWLEDGEMENTS}

We thank McKenzie Allen (USDA), Samuel Brandt (USDA), Lee Carper (USDA), John Cullum (USDA), Morgan Douglas (USDA), Nicole Halbrendt (PSU FREC), Chris Hott (USDA), Marcelo Zanelato Nunes (PSU FREC), Britany Poling (NDSU), Ann Rucker (Rutgers), Tony Rugh (USDA), Nick Serata (Rutgers), and Lauran Shaak (PSU FREC) for their excellent technical assistance. This work was funded by Northeast SARE Grant\#LNE14-334. We would like to generously thank our cooperating growers for allowing us to conduct this research on their farm, including those from Maryland, New Jersey, Pennsylvania, Virginia, and West Virginia. The use of trade names is for the purposes of providing scientific information only, and does not constitute endorsement by the United States Department of Agriculture. The USDA is an equal opportunity employer.

\section{SUPPORTING INFORMATION}

Supporting information may be found in the online version of this article.

\section{REFERENCES}

1 Xu J, Fonseca DM, Hamilton GC, Hoelmer KA and Nielsen AL, Tracing the origin of US brown marmorated stink bugs, Halyomorpha halys. Biol Invasions 16:153-166 (2014).

2 Hoebeke ER and Carter ME, Halyomorpha halys (Stål) (Heteroptera: Pentatomidae): a polyphagous plant pest from Asia newly detected in North America. Proc Entomol Soc Wash 105:225-237 (2003).

3 Valentin R, Nielsen AL, Wiman NG, Lee D-H and Fonseca DM, Global invasion network of the brown marmorated stink bug, Halyomorpha halys. Sci Rep 7:9866 (2017).

4 USAA, Losses to Mid-Atlantic Apple Growers at \$37 Million from Brown Marmorated Stink Bug. United States Apple Association, Vienna, VA (2011).

5 Leskey TC and Nielsen AL, Impact of the brown marmorated stink bug in North America and Europe: history, biology, ecology, and management. Annu Rev Entomol 63:599-618 (2018).

6 Acebes-Doria AL, Leskey TC and Bergh JC, Injury to apples and peaches at harvest from feeding by Halyomorpha halys (Stål) (Hemiptera: Pentatomidae) nymphs early and late in the season. Crop Prot 89:58-65 (2016)

7 Leskey TC, Short BD, Butler BR and Wright SE, Impact of the invasive brown marmorated stink bug, Halyomorpha halys (Stål), in mid-Atlantic tree fruit orchards in the United States: case studies of commercial management. Psyche 2012:1 - 14 (2012).

8 Fogain R and Graff S, First records of the invasive pest, Halyomorpha halys (Hemiptera: Pentatomidae), in Ontario and Quebec. J Entomol Soc Ontario 142:45-48 (2011).

9 Wermelinger B, Wyniger D and Forster B, First records of an invasive bug in Europe: Halyomorpha halys Stål (Heteroptera: Pentatomidae), a new pest on woody ornamentals and fruit trees? Bull la Société Entomol Suisse 81:1-8 (2008).

10 Kriticos DJ, Kean JM, Phillips CB, Senay SD, Acosta H and Haye T, The potential global distribution of the brown marmorated stink bug,
Halyomorpha halys, a critical threat to plant biosecurity. J Pest Sci 90:1033-1043 (2017). https://doi.org/10.1007/s10340-017-0869-5.

11 Haye T, Gariepy T, Hoelmer KA, Rossi JP, Streito JC, Tassus X et al., Range expansion of the invasive brown marmorated stink bug, Halyomorpha halys: an increasing threat to field, fruit, and vegetable crops worldwide. J Pest Sci 88:665-673 (2015).

12 Zhu G, Bu W, Gao Y and Liu G, Potential geographic distribution of brown marmorated stink bug invasion (Halyomorpha halys). PLoS One 7:e31246 (2012).

13 Weber DC, Morrison WR III, Khrimian A, Rice KB, Leskey TC, Rodriguez-Saona $\mathrm{C}$ et al., Chemical ecology of Halyomorpha halys: discoveries and applications. J Pest Sci 90:989-1008 (2017). https:// doi.org/10.1007/s10340-017-0876-6.

14 Leskey TC, Wright SE, Short BD and Khrimian A, Development of behaviorally-based monitoring tools for the brown marmorated stink bug (Heteroptera: Pentatomidae) in commercial tree fruit orchards. J Entomol Sci 47:76-85 (2012).

15 Khrimian A, Zhang A, Weber DC, Ho H-Y, Aldrich JR, Vermillion KE et al., Discovery of the aggregation pheromone of the brown marmorated stink bug ( Halyomorpha halys ) through the creation of stereoisomeric libraries of 1-bisabolen-3-ols. J Nat Prod 77:1708-1717 (2014).

16 Weber DC, Leskey TC, Walsh GC and Khrimian A, Synergy of aggregation pheromone with methyl ( $E, E, Z)$-2,4,6-decatrienoate in attraction of Halyomorpha halys (Hemiptera: Pentatomidae). J Econ Entomol 107:1061 - 1068 (2014).

17 Leskey TC, Agnello A, Bergh JC, Dively GP, Hamilton GC, Jentsch P et al., Attraction of the invasive Halyomorpha halys (Hemiptera: Pentatomidae) to traps baited with semiochemical stimuli across the United States. J Econ Entomol 44:746-756 (2015)

18 Morrison WR III, Milonas P, Kapantaidaki DE, Cesari M, Di Bella E, Guidetti R et al., Attraction of Halyomorpha halys (Hemiptera: Pentatomidae) haplotypes in North America and Europe to baited traps. Sci Rep 7:16941 (2017).

19 Morrison WR III, Park C-G, Seo BY, Park Y-L, Kim HG, Rice KB et al., Attraction of the invasive Halyomorpha halys in its native Asian range to traps baited with semiochemical stimuli. J Pest Sci 90:1205-1217 (2017). https://doi.org/10.1007/s10340-016-0816-x.

20 Venugopal PD, Dively GP and Lamp WO, Spatiotemporal dynamics of the invasive Halyomorpha halys (Hemiptera: Pentatomidae) in and between adjacent corn and soybean fields. J Econ Entomol 108:2231-2241 (2015).

21 Joseph SV, Stallings JW, Leskey TC, Krawczyk G, Polk D, Butler B et al., Spatial distribution of brown marmorated stink bug (Hemiptera: Pentatomidae) injury at harvest in mid-Atlantic apple orchards. J Econ Entomol 107:1839-1848 (2014).

22 Blaauw BR, Jones VP and Nielsen AL, Utilizing immunomarking techniques to track Halyomorpha halys (Hemiptera: Pentatomidae) movement and distribution within a peach orchard. PeerJ 4:e1997 (2016).

23 Rice KB, Troyer RR, Watrous KM, Tooker JF and Fleischer SJ, Landscape factors influencing stink bug injury in mid-Atlantic tomato fields. J Econ Entomol 110:94-100 (2016).

24 Blaauw BR, Polk D and Nielsen AL, IPM-CPR for peaches: incorporating behaviorally-based methods to manage Halyomorpha halys and key pests in peach. Pest Manag Sci 71:1513-1522 (2015).

25 Nielsen AL, Dively G, Pote JM, Zinati G and Mathews C, Identifying a potential trap crop for a novel insect pest, Halyomorpha halys (Hemiptera: Pentatomidae), in organic farms. Environ Entomol 45:472-478 (2016).

26 Soergel DC, Ostiguy N, Fleischer SJ, Troyer RR and Krawczyk G, Sunflower as a potential trap crop of Halyomorpha halys (Hemiptera: Pentatomidae) in pepper fields. Environ Entomol 44:1581-1589 (2015).

27 Mathews CR, Blaauw B, Dively G, Kotcon J, Moore J, Ogburn E et al., Evaluating a polyculture trap crop for organic management of Halyomorpha halys and native stink bugs in peppers. J Pest Sci 90:1245-1255 (2017). https://doi.org/10.1007/s10340-017-0838-z.

28 Blaauw BR, Morrison WR, Mathews C, Leskey TC and Nielsen AL, Measuring host plant selection and retention of Halyomorpha halys by a trap crop. Entomol Exp Appl 163:197-208 (2017).

29 Short BD, Khrimian A and Leskey TC, Pheromone-based decision support tools for management of Halyomorpha halys in apple orchards: development of a trap-based treatment threshold. J Pest Sci 90:1191-1204 (2017). https://doi.org/10.1007/s10340-0160812-1. 
30 Morrison WR, Lee DH, Short BD, Khrimian A and Leskey TC, Establishing the behavioral basis for an attract-and-kill strategy to manage the invasive Halyomorpha halys in apple orchards. J Pest Sci 89:81-96 (2016).

31 Navarro-Llopis V, Primo J and Vacas S, Efficacy of attract-and-kill devices for the control of Ceratitis capitata. Pest Manag Sci 69:478-782 (2013).

32 Morrison WR, Lee DH, Reissig WH, Combs D, Leahy K, Tuttle A et al., Inclusion of specialist and generalist stimuli in attract-and-kill programs: their relative efficacy in apple maggot fly (Diptera: Tephritidae) pest management. Environ Entomol 45:974-982 (2016).

33 Leskey TC, Piñero JC and Prokopy RJ, Odor-baited trap trees: a novel management tool for plum curculio (Coleoptera: Curculionidae). J Econ Entomol 101:1302-1309 (2008).

34 El-Shafie HAF, Faleiro JR, Al-Abbad AH, Stoltman L and Mafra-Neto A, Bait-free attract and kill technology (Hook ${ }^{\mathrm{TM}} \mathrm{RPW}$ ) to suppress red palm weevil, Rhynchophorus ferrugineus (Coleoptera: Curculionidae) in date palm. Fla Entomol 94:774-778 (2011).

35 Kroschel J and Zegarra O, Attract-and-kill as a new strategy for the management of the potato tuber moths Phthorimaea operculella (Zeller) and Symmetrischema tangolias (Gyen) in potato: evaluation of its efficacy under potato field and storage conditions. Pest Manag Sci 69:1205-1215 (2013).

36 Pfeiffer D, Bergh JC, Wilson JM, Frank DL, Hooks CRR. 2018 Spray Bulletin for Commercial Tree Fruit Growers. Virginia, West Virginia, and University of Maryland Extension, Publication \#456-419, Blacksburg, VA (2018). Available: http://pubs.ext.vt.edu/content/dam/pubs_ ext_vt_edu/456/456-419/456-419.pdf [12 June 2018].

37 Leskey TC, Khrimian A, Weber DC, Aldrich JC, Short BD, Lee D-H etal., Behavioral responses of the invasive Halyomorpha halys (Stal) to traps baited with stereoisomeric mixtures of 10,11-epoxy-1-bisabolen-3-ol. J Chem Ecol 41:418-429 (2015).

38 Morrison WR III, Cullum JP and Leskey TC, Evaluation of trap designs and deployment strategies for capturing Halyomorpha halys (Hemiptera: Pentatomidae). J Econ Entomol 108:1683-1692 (2015).

39 Tomek WG and Kaiser HM, Agricultural Product Prices. Cornell University Press, Ithaca, NY 408 pp (2014).

40 Aho KA, Foundational and Applied Statistics for Biologists Using R. CRC Press, Boca Raton, FL, pp. 1-596 (2014).

$41 \mathrm{R}$ Core Team. R: A Language and Environment for Statistical Computing. Vienna, Austria: R Foundation for Statistical Computing; 2016. Available: https://www.r-project.org/.
42 Miller JR, Adams CG, Weston PA and Schenker JH, Trapping of Small Organisms Moving Randomly: Principles and Applications to Pest Monitoring and Management. Springer, Berlin, $108 \mathrm{pp}$ (2015).

43 Vargas RI, Pinero JC, Mau RF, Jang EB, Klungness LM, Mcinnis DO et al., Area-wide suppression of the Mediterranean fruit fly, Ceratitis capitata, and the Oriental fruit fly, Bactrocera dorsalis, in Kamuela, Hawaii. J Insect Sci 10:135 (2010).

44 Tillman PG and Cottrell TE, Case study: trap crop with pheromone traps for suppressing Euschistus servus (Heteroptera: Pentatomidae) in cotton. Psyche 2012:1 - 10 (2012).

45 Morrison WR III, Allen M and Leskey TC, Behavioral response of the invasive Halyomorpha halys (Hemiptera: Pentatomidae) to host plant stimuli augmented with semiochemicals in the field. Agric For Entomol 20:62-72 (2017). https://doi.org/10.1111/afe.12229.

46 Lee D-H and Leskey TC, Flight behavior of foraging and overwintering brown marmorated stink bug, Halyomorpha halys (Hemiptera: Pentatomidae). Bull Entomol Res 105:566-573 (2015).

47 Morrison WR III, Poling B and Leskey TC, The consequences of sublethal exposure to insecticide on the survivorship and mobility of Halyomorpha halys (Hemiptera: Pentatomidae). Pest Manag Sci 73:389-396 (2017).

48 Cissel B, Whalen J, Dively GP, Hooks CRR, Patton T, Venugopal PD et al., Brown Marmorated Stink Bug: Biology and Management in Mid-Atlantic Soybeans. Virginia Tech Extension, \#ENTO-168NP, Blacksburg, VA (2015).

49 Gardiner MM, Landis DA, Gratton C, DiFonzo CD, O'Neal M, Chacon JM et al., Landscape diversity enhances biological control of an introduced crop pest in the north-central USA. Ecol App/ 19:143-154 (2009).

50 Kuhar TP, Short BD, Krawczyk G and Leskey TC, Deltamethrinincorporated nets as an integrated pest management tool for the invasive Halyomorpha halys (Hemiptera: Pentatomidae). J Econ Entomol 110:543-545 (2017).

51 Smitley DR, Doccola JJ and Cox DL, Multi-year protection of ash trees from emerald ash borer with a single trunk injection of emamectin benzoate, and single-year protection with an imidacloprid basal drench. Arboric Urban For 36:206-211 (2010).

52 Zhang JM, Wang H, Zhao LX, Zhang F and Yu GY, Damage to an organic apple orchard by the brown marmorated stink bug, Halyomorpha halys and its control strategy. Chinese Bull Entomol 44:898-901 (2007).

53 Bergmann EJ, Venugopal PD, Martinson HM, Raupp MJ and Shrewsbury PM, Host plant use by the invasive Halyomorpha halys (Stål) on woody ornamental trees and shrubs. PLOS One 11:e0149975 (2016). 